\title{
1. Introduction: work, life and time in the new economy
}

\section{Diane Perrons, Linda McDowell, Colette Fagan, Kath Ray and Kevin Ward}

The organization and composition of paid work and the structure of families have changed dramatically in recent decades and so too has the context within which individuals and families organize their lives. Contemporary times are characterized by the widespread, albeit uneven, use of information and computing technologies and greater economic, political and social communications between peoples and between states. As a consequence states in Northern and Western Europe have become more homogenous and moved closer to the United States in terms of their economies and working patterns. The service sector has become dominant, paid work has become feminized and more flexible and families are more varied in their composition. The significance of the male breadwinner, female caregiver model, dominant in the mid-twentieth century, has declined in both Europe and the United States, but the ensuing care deficit has not been resolved and to varying degrees growing numbers of both dual- and single-earning households struggle to find time to combine paid work with caring (Heyman, 2000). These changes result from the interrelations between the shifting economic and political context, in particular a more competitive and global economic environment and changing lifestyle preferences with regard to living and working arrangements.

In advanced industrial societies new lifestyles, forms and patterns of work became increasing apparent towards the end of the twentieth century and terms such as 'the risk society', 'late modernity', 'knowledge society' and 'new economy' were used to portray the new era. The global dimension of change was also noted and increasing references were made to concepts such as 'one world', 'globalization', 'global economy' and 'global transformation' to depict the increasing interconnections between people and places, and to varying degrees the implications of such relations (Perrons, 2004a). While overall there have been massive increases in wealth, especially in Western nations, attention has also been drawn to some of the negative consequences of these changes in terms of widening economic inequalities between and 
within countries (Milanovic, 2002; Wade, 2001; Piketty and Saez, 2003; Rifkin, 2004) and the suffering endured by many people, especially women and children in poorer countries (Bhavani et al., 2003; UNICEF, 2004).

Collectively we refer to these phenomena as the 'new economy' and this book aims to explore how these macro-level changes are affecting the micro organization of daily life, with particular reference to working patterns and gender divisions in Northern and Western Europe and the United States. We also consider the various policy responses to these changes and the extent to which they promote greater gender equity, recognizing the potentially heterogeneous gender interests of different groups of women and men as well as the diverse patterning of gender relations and divisions across different social domains.

This introduction identifies some of the key issues, and outlines the context in which all countries have experienced change to a greater or lesser degree. The issues are explored in depth in the chapters, which consist of case studies of specific countries - France, Norway, Sweden, the UK and the USA - and thematic comparative studies, across Europe and the US. The majority of the chapters derive originally from the ESRC seminar series on Work, Life and Time in the New Economy', ${ }^{1}$ and reflecting these contributions the collection is focused on the analysis of Western societies.

\section{THE NEW ECONOMY}

The last ten years have seen academics in a range of disciplines, as well as the press, begin to use the term the 'new economy'. However, there is little agreement about what is meant by it. Orthodox economists use the term narrowly to refer to the mid- to late-1990s boom, which fuelled and was fuelled by the growth of dot.com companies, but in contrast to the past, wage increases were only moderate, generating a unique period of inflation-free growth (Greenspan, 1998). With the slowdown in the rates of economic growth and the collapse of the dot.com boom this interpretation has been rather discredited but the idea of a high-technology knowledge-based 'new economy' remains important, with writers such as Manuel Castells (2000) and Diane Coyle and Danny Quah (2002) emphasizing how ICTs (information and communication technologies) have revolutionized the organization of business and commerce. Promotion of 'knowledge' work as crucial to economic success remains a central tenet of EU policy most clearly expressed in the Lisbon Strategy (European Parliament, 2000).

More pessimistic interpretations of the new economy however refer to growing risk and insecurity (Beck, 2000), falling fertility (Esping-Andersen, 2002), the fragmentation of communities (Sennett, 1998), and the erosion of 
traditional social rhythms and practices, as the boundaries around work dissolve, raising the intensity of work as people are never 'off-line'.

Danny Quah (1996) analytically links the positive and negative dimensions of the new economy, and argues that its emergence is associated with widening social divisions. In his analysis some of the essential characteristics of the knowledge-based economy which contribute to economic growth, also increase economic inequality. For Quah, a knowledge good is anything that can in principle be digitized and people producing these goods are knowledge workers. Thus pop and rock singers as well as architects, to the extent that their designs can be digitized, are knowledge workers as well as those working more directly with ICTs. Knowledge goods are infinitely expansible, that is they can be replicated at very low cost; and they are non-rival - thus one person's consumption does not prevent another's. These properties should tend to generate greater equality. However as Quah (1996) explains, knowledge goods are also characterized by increasing economies of scale because although they can be replicated and thus have very low marginal costs, the cost of the first product, for example a new computer game, can be very high, thus large firms tend to dominate the market and having done so they create a range of related products, locking consumers in to their particular brand. A further property is the superstar effect, which refers to consumers' preferences for products of greater renown even though they may be barely distinguishable from competitors. Given the weightlessness of knowledge products there are few constraints on market size so the producers can capture an increasing share of the market. As knowledge goods and knowledge workers become more important in the economy, social and spatial inequalities will tend to increase. Qhah implies that these inequalities are rather random and in the new economy social mobility is greater such that the poor have chances of becoming rich. However, ethnicity, sexual orientation, class and gender typically code work, so the widening social divisions are likely to reinforce existing structural inequalities in the labour force. Gender inequalities are particularly likely to be intensified in the new economy owing to the expansion of carework to replace women's domestic labour as they enter employment in growing numbers.

Carework is typically low paid in market economies because it is highly labour intensive with limited scope for productivity gains, which perhaps helps to explain why, despite the proliferation of work-life balance policies, gender inequality in the labour market continues (Perrons, 2004b). In the case of marketized domestic services, class divisions arising from the working class servicing the middle class also generate divisions between women. In addition to these changes relating to the composition of employment, there have been contradictory changes in the contractual status of employees associated with the implementation of protective employment legislation on the one hand and 
deregulation and individualized contracts on the other. These developments are associated with neo-liberalism but the outcomes are contingent, hence the value of comparative empirical investigation.

One of the drivers of contemporary change is the worldwide supremacy of neo-liberalism or the Washington consensus, ${ }^{2}$ referring collectively to trade liberalization, economic deregulation (though in the area of gender equity there is more regulation - see Walby, 2002), privatization, active labour market policies and fiscal discipline in conjunction with the spread of formal democracy. States adhering to this philosophy are then constrained in terms of their freedom to manage their economies, and firms are compelled to operate within the intensely competitive global market, which shapes their internal working patterns and practices.

Competition is pervasive; neither private firms nor the state can afford any slack or porosity in their organizations. Firms trading internationally have to be competitive in global markets and so make similar demands on their suppliers, including the state, prompting pressure for cost savings, privatization and rationalization of public sector services (Streeck, 1999). Indeed these competitive pressures have contributed to widening economic inequality and social divisions within and between states as well as to new forms of work and the feminization of employment.

In all sectors the regularly employed workforce is pared down to a minimum, supplemented by more flexibly employed workers, whose working times vary with fluctuations in demand. Correspondingly work intensity has increased in terms of the speed of work and tightness of deadlines (Green, 2003).

Contemporary management practices can internalize the pressures by, in effect, turning employees into their own managers who are "held responsible for their sales, their products, their branch, their store, etc. as though they were independent contractors, even though in reality they are simple wage labourers' (Bourdieu, 1998: 2) which intensifies the working environment and contributes to ideas about the time squeeze. Thus employees also experience pressure from their colleagues as well as clients (Burchell, this volume); and as Julia Brannen (2005) comments, as we seemingly take more control over our time, so time takes control of us and our apparent control over working time only means that we spend longer working. More polemically it has been suggested that 'the very best workers are now those who never sleep, never consume, never have children, and never spend time socialising outside of work' (Carnoy, 2000: 143). While fertility has fallen and remains below replacement level in the EU25 at 1.6 (US, 2.07) (Eurostat, 2004b) and remains a policy concern in terms of the future labour supply, in reality contemporary workers, especially the middle-aged, are likely to have caring responsibilities for either children or the elderly and in many cases for both, generating a 
potential caring deficit as women, the traditional carers, have become more active in the labour market. ${ }^{3}$

All of these changes in the conditions under which people live and labour make it more difficult to realize equal opportunities or family-friendly policies as people feel under pressure not to exercise their entitlements to breaks, time off or holidays. For those on non-permanent contracts, the choice is often a more straightforward one, as they may have few, if any, entitlements to exercise.

These arguments have so far been presented in rather abstract terms and as though changes largely reflect market logic, but all markets operate within social and political frameworks and institutions. Correspondingly they are open to modification by prevailing cultural norms and political and social pressures, including state legislation and regulation as well as action by trade unions. In the European Union these social and political frameworks are shaped both by supranational strategies relating to economic stability, growth and employment, as well as by country-specific policy regimes and institutional arrangements. ${ }^{4}$ Thus while European Union countries may share some ideals relating to the European Social Model, which differs from the more neo-liberal philosophy prevailing in the Unites States, the actual policies and frameworks in different states will continue to vary and are discussed in more detail in the context of specific countries in the chapters to follow.

\section{STATE POLICIES}

As a consequence of this more competitive environment the sustainability and desirability of the European Social Model, which sought to combine market efficiency with social solidarity, is being challenged. While social cohesion remains in parts of the political vocabulary, the driving force of policy is undoubtedly productivity and economic growth. The European Union compares its performance negatively with the US ${ }^{5}$ in respect of employment and growth, and with Asia, especially China and India, where productivity can be similar but wages a minute fraction of those in the West. To promote growth the European Union developed and subsequently endorsed the Lisbon Strategy (2000) through which it sought to become 'the most dynamic and competitive knowledge based economy in the world, capable of sustaining economic growth with more and better jobs and greater social cohesion and respect for the environment' (EC, 2004a). However this strategy was to run alongside the Growth and Stability Pact adopted in 1997, which is directed towards securing budgetary discipline and the short-term stability of the currency, and it is not clear that these strategies are compatible (see Arnaud, 2003). The Growth and Stability Pact is focused on the nominal economy and 
issues such as low inflation, balanced budgets and limited public expenditure, while the Lisbon strategy is oriented towards growth and employment expansion. Employment targets are specific: expanding the overall employment rate to 70 per cent, and the female rate to 60 per cent by 2010 . To realize the female rate, further targets for childcare were set in 2002 of 90 per cent for children between three years old and the statutory school age, and 33 per cent for children under three. ${ }^{6}$ Clearly such targets are likely to require an increase in public expenditure, something limited by the growth and stability policy.

Thus contradictions exist within economic policy and between economic and social policies at the supranational level and it has been argued that 'if we want to preserve and improve our social model we have to adapt it'. This statement was made in the Kok (2004) report, which makes renewed arguments for further liberalizing the EU economy and the labour market through increased adaptability or flexibility. The old European social model in terms of more regulated employment relations therefore seems to be waning and displaced by a growing similarity, especially in terms of flexible and more intensive working patterns, with the United States, where there has been little tradition of collaboration between the social partners.

At the same time however, and apparently running against this trend, EU social policy is also expanding into new areas. For example the EU is extending its area of competency into the family by developing a number of policies concerned with reconciling paid work and family life, an area previously considered outside of its remit. In addition to the targets for childcare the EU Strategy for Gender Equality (EC, 2000b) has implemented gender mainstreaming, which requires that all policies be examined for their gender differentiated effects, in addition to more specific actions concerned with the gender pay gap, civil rights and gender stereotypes. In this respect the EU is similar to other supranational institutions including the United Nations, the World Bank and the OECD, all of which have expressed concern about gender equality and women's empowerment and, in the case of the latter, reconciling paid work and family life, something also highlighted in the EU's gender equality strategy.

It is likely that these measures are motivated as much by the economic concern for an expanded workforce together with demographic unease about low fertility and aging as by an intrinsic desire for gender equity. For example the OECD (2002) in its series of reports, 'Babies and Bosses' recognizes that family-friendly policies can increase the living standards of parents and children and thus are a goal in themselves in terms of enhancing gender equality and child development, but nevertheless clearly states that: 'getting the right policy in place will promote other societal goals ... [in particular will] ... allow aggregate labour supply and employment to be increased' (OECD, 
2002: 5). Likewise firms in both the US and EU have commercial reasons for pursuing diversity strategies (see Fisher, this volume).

The unresolved tension or conflict between economic and social policy remains however, as increasing care provision in a more liberal, competitive and global economy would require significant increases in public expenditure owing to the inherent characteristics of carework, in particular its low productivity as described in traditional neo-classical terms (Himmelweit, 2005: Himmelweit and Perrons, 2005). Consequently carework tends to be underprovided in market economies or restricted to an elite able to meet the high costs. Thus to achieve the childcare targets state-subsidized provision will almost certainly be required. Yet the state has difficulty raising funds from the private sector given the competitive environment, and is limited in its capacity to raise debt given the restrictions on government spending and budget deficits in the Growth and Stability Pact, or in the case of the US from its adherence to neo-liberalism in general and the preference for regressive cuts in taxation exercized during the Bush presidency (from 2001 to the present).

From a feminist perspective neither changes in work organization and family composition nor the introduction of apparently gender-aware policies are entirely unambiguously positive developments. Whilst on the one hand, policies that take a holistic view of the economy by taking cognisance of reproductive work (Elson, 1998) and genuinely empower women by enabling them to lead 'lives they have reason to value' (Sen, 2000: 3) are clearly welcome, it is not clear that the contemporary interest in care by national and supranational organizations meets these aspirations. Indeed it is important to consider whether current policies are driven as much by the desire to expand the employment rate and enhance economic growth in the quest for a competitive knowledge-based economy as by a desire for equality, and to consider what implications this has for achieving gender equity. The measures would seem to be progressive for women; however it is important to consider what the outcomes are for different groups of women (and men) positioned differently in economic terms. Without wider and more deep-seated changes in the gender composition of employment, in particular in relation to segregation and the monetary rewards given to jobs disproportionately done by women, in the valuation of carework and care relations and in the domestic division of labour between women and men, increasing female employment may lead to widening inequalities between women and to an increase in women's overall workload.

\section{GENDER DIVISIONS IN CARING AND PAID WORK}

Research on gender patterns in working time shows that men in households with children tend to work longer hours than men in general, and typically 
their wives or partners work less, even when employed full-time (Fagan, 2001; Anxo and Boulin, 2004). Nevertheless if paid work and caring work are combined, women on average work longer hours than men and it is almost invariably women that make the compromises necessary to fit paid work around the family and who experience the anxiety and stress of combining these roles (Moen, 2003; Eurostat, 2004; McDowell et al., 2005 and Crompton and Brockmann, this volume). The details of this picture vary within and between European countries and between these countries and the United States, but the broad trends are consistent (Messenger, 2004). The experiences of individuals also vary depending on their actual working hours and the level of employer and state support, both of which vary between countries. There are additional variations between employers and regions within the same country, as the policies of firms vary and are only partly conditioned by the national context, and the application of national and firm policies can vary regionally depending on the actual resources available.

In terms of paid employment gender divisions are also persistent. Both vertical and horizontal employment segregation remain entrenched. Segregation in employment builds upon and probably reinforces gender stereotypes, with women being seen as naturally suited to caring work but out of place in jobs dealing with complex machinery, involving physical labour, or in managerial positions, especially as the managers and supervisors of men. Only 21 per cent of the EU15 workforce has a woman as their immediate superior while 63 per cent have a man, the remainder having no immediate supervisor. Women managers and supervisors are much more likely to be supervising other women, and less than 10 per cent of employed men have a woman manager (Fagan and Burchell, 2002). In terms of horizontal segregation women are over-represented in activities relating to nurturing, care, clerical work and sales, while men are over-represented in sectors and occupations involving money, management and machinery. For example women hold 66 per cent of clerical and sales jobs, while men hold 80 per cent or more of jobs in the armed services, craft and related trades, plant and machine operators, and 66 per cent of skilled agricultural and fishery jobs. Further, while women have been gaining entry into professional jobs, segregation also exists among the professions, with men being overrepresented in mathematical and engineering professions and women overrepresented in health and education. These statistics are for the EU15 as a whole, and while the degree of segregation varies between member states, all share this general pattern (Fagan and Burchell, 2002; Rubery et al., 1999). Similar patterns of vertical and horizontal segregation exist in the USA and in both cases contribute to the continuing gender pay gap between women and men (Anker, 1998).

In the USA the drift to the right in politics has led to successive cuts in Diane Perrons, Linda McDowell, Colette Fagan, Kath Ray, and Kevin Ward - 9781845428976 
welfare expenditure and taxes, as a consequence of which, although employment rates are high, wages have not increased by a corresponding amount, leading to an expansion of the working poor, many of whom are single mothers pressed into the labour market through the Welfare To Work programme. Work has become more flexible by contract and in terms of working hours, and despite lack of formal maternity provision the US has higher female participation rates compared to European countries. However a glass ceiling remains. Women hold only eight CEO-ships, 13.6 per cent of board seats and 15.7 per cent of top executive jobs in the Fortune 500. These statistics formed the essence of the ' 85 Broads campaign' and the idea of holding a women's 'buycot day' in order to demonstrate the economic power that women could exert as consumers, given that 85 per cent of all purchases in the USA are either made or influenced by women ${ }^{8}$ (see Fisher, this volume). Similarly in Norway there was a campaign for women to stop work from mid October each year to reflect the fact that women on average continue to earn only 86 per cent as much as men.

Given this situation it is clear that simply expanding the female employment rate without addressing issues of employment composition and pay will not by itself resolves gender inequality. Similarly developing flexible hours and flexible services (Boulin; Morris and Pillinger this volume) may better enable people to combine paid work with caring, but not be sufficient to challenge gender divisions of labour in work and at home and thus promote more deepseated gender equality.

While many states are now assuming an adult citizen rather than a male breadwinner model in terms of their policies (see Lewis, 2002) examining the actual position of women in the labour market makes it clear that the reality is more likely to be a one-and-a-half earner model with women disproportionately making the career compromises and putting at risk their long-term economic well-being. At the same time however, even with many women devoting a considerable part of their time to caring, a deficit nevertheless remains and these concerns are intensified by the changing composition of the family which has been the traditional source of care.

\section{CARE DEFICIT}

Concern about the caring deficit has been heightened by dramatic changes in family composition. The statistics almost speak for themselves. To varying degrees across the European Union the numbers divorcing, the proportion of children born outside marriage, and the proportion of one-person households have been increasing while the numbers marrying have declined. In the EU the average divorce rate is 1.9 per 1000 but there are wide variations, with low 
levels in Southern Europe and higher levels elsewhere. For example the divorce rate was 0.9 per cent in Spain, compared to 3 per cent in Belgium in 2002, which is closer to the US figure of 3.9 (2004) where nearly 50 per cent of marriages end in divorce (National Statistics, 2004; NVSS, 2004; Whitehead and Popenoe, 2004). In fact in the US the divorce rate is now declining following a peak in the early 1980s, but this is partly because fewer people marry. These changes can be viewed positively, as people are less bound by tradition and freer to author their own lives (see Hardill and van Loon, this volume), or negatively in terms of heralding a crisis in the family, both intrinsically and because of the role played by the family as the traditional provider of care regardless of normative values about the family as an institution.

Changes in household and family structures also include an increase in dual-earning households which are now the dominant form among those of working age in the EU15, and the rate of increase in dual-earning households with at least one child has been particularly marked in most states during the 1990s (Eurostat, 2002). In the EU the modal pattern among these households (with and without children) is for the man to work long full-time hours (40+) and the woman to work long part-time hours (20+). However there are significant variations between countries, with the UK having a highly polarized gender division with men working very long hours and women very short hours (Fagan, 2001; Bishop, 2004). France has a more balanced distribution and the smallest proportion of men working over 40 hours, partly as a consequence of the 35-hour week (see Fagnani and Letablier, this volume). There has also been an increase in the number of single-parent earner households; all of these changes reflecting the social expectation that all people will be labour market active. In the United States there has been an increase in the diversity of working hours with more people working very few and more people working very many hours, as well as greater variation in the times that people work (Presser, this volume). In fact the number of hours worked by dual-earner households with children there has remained stable between 1992 and 2002, averaging at 79 a week, but there has been an increase in the number of these households as well as in single-parent earner households (EPF, 2004). These are the households that experience time pressures and in some cases greater stress, even though gender divisions in working hours remain.

Thus families are becoming increasingly fluid and household working hours have been increasing. This has resulted in a growing recognition that the male breadwinner, female caregiver model is no longer a social reality and is neither economically desirable nor sustainable (Esping-Andersen, 1999; Lewis, 2001). Nevertheless the costs of providing care are considerable, especially in the context of public sector financial stringency. How this ensuing care deficit 
is addressed varies between countries and this has different implications for the gender division of labour and for gender equity. Some of these implications are drawn out in the chapters that follow.

\section{COMPARATIVE ANALYSIS}

Although many of the processes in terms of the organization of work and work-life balance policies discussed above are universal in their existence, they are not universal in terms of their effects, and so rigorous and differentiated academic inquiry is required to document how these patterns vary over time and between countries. Even though the power of nation-states may have been redefined in the context of a global economy with supranational institutions, economic and social policy continues to be nationally differentiated. State policies reflect different national traditions, cultures and contexts and thus influence working patterns, family choices and gender roles in different ways. These differences have significant implications for the overall levels of economic inequality within states, the degree of gender equity, and on a more practical level the actual working times, provision of eldercare and childcare: factors which shape the specific context in which contemporary families negotiate their household strategies and gender division of labour between paid and unpaid work.

While there may be some trends towards convergence in social policies emanating from adherence to the neo-liberal consensus, exploring continuing differences between states provides an important challenge to the idea that the move to neo-liberalism is inevitable irreversible and undifferentiated. In reality, commitment to the neo-liberal model varies and is far more diluted in countries rooted in corporatist and social democratic traditions that lie behind the European Social Model in comparison to the UK or the US. The contributions to this book examine a range of issues such as the degree of work inequality, the patterning of working hours, degrees of work intensity and stress, cultures of parenting, the provision of childcare, and equal opportunities policies across different countries of the EU and the US. They thus contribute to our understanding of spatial variations in gender divisions and how these are shaped by different state responses to women's labour market participation across Europe and the US.

\section{THE CHAPTERS}

To explore these issues this book includes a range of studies examining how these broader changes are experienced in daily life in different national 
contexts. The focus is on changing working patterns and how families in different nation-states manage their reproduction from one day to the next and over time, assessing in particular what the impact has been on gender divisions. Potentially the new economy extends the temporal and spatial boundaries of paid work, and correspondingly potentially widens the opportunities for people seeking paid work, especially those with caring responsibilities (though with the risk of work becoming boundless). In reality however, as the more detailed studies indicate, the effects are more complex and differentiated.

The case studies do not address identical issues nor do they address them in the same way. While there are common themes, including new forms of work, new working times, feminization of employment, gender divisions and ways of combining paid work with caring, the national case studies are framed within debates and issues that reflect their specific contexts and consequently highlight the implicit differences between states in terms of social, cultural and political traditions, the existing provision of state supportive care services and contemporary concerns.

The Nordic countries in particular are framed within a social democratic welfare tradition with an adult citizen model and only a weak male breadwinner ethos. Nevertheless the Swedish case studies indicate that gender inequality in pay systems is pervasive and is likely to reappear when the more liberal and individualized pay systems are added on to an existing corporatist collective bargaining framework (Gonäs, Bergman and Rosenberg, this volume). At the same time the ethos of care as a state obligation is clearly evident in both Sweden and Norway. In Sweden, care policies have been developing independently from, indeed almost counter to, the economic trends and continued to expand despite falling levels of employment following the economic crisis of the early 1990s and subsequent membership of the EU in 1995 and adherence to its policies (Nyberg, this volume). Likewise in Norway consistent efforts have been made through state policies to involve fathers in childcare (Brandth and Kvande, this volume). The French case also demonstrates the more corporatist tradition through the resistance to neoliberal deregulation with the introduction of the 35-hour week, ${ }^{9}$ although the reduction in paid work has not been sufficient to lead to any major changes in the gender division of labour outside of the workplace and the continuation of the 35-hour week is itself currently threatened (Fagnani and Letablier, this volume). By contrast the US and the UK reflect the greater flexibility and individualization found in the neo-liberal economies, though there are some structural constraints to degree of flexibility (see Duncan, this volume).

The book is divided into five parts, each preceded by a short introduction, which highlights some of the issues and brings a comparative perspective to bear on the chapters. The overarching themes from the five parts are then 
drawn together in the conclusion in Chapter 16. In this way we hope to have preserved the depth that single case studies provide while not overlooking the comparative dimension, which makes the different cases so interesting.

Part I explores the changing character of work and working times and whether the popular perceptions of increased intensity and insecurity are matched by quantitative and qualitative evidence and the implications of these changes for health and work-life balance. These issues are explored further in Part II, which also considers the implications of the increase in the feminization of employment in different national contexts for managing work life balance. It clearly demonstrates different national perspectives or responses to the destabilization of the male breadwinner, female carer model, but also how work-life balance issues can be affected by other national policies, in the case of France for example by the reduction in working time motivated by concern with high levels of unemployment. This part also considers the impact of new working times and new employment relations on work-life balance and stress.

The chapters in Part III pursue these issues by focusing on decision making at the household level and the influence of social class, geographical context and state policy in influencing the gender division of labour within the household. Part IV takes a rather different direction by examining the ways in which new technologies and city time policies can be used to deliver local government services more effectively to match the needs of a more feminized and flexible workforce, given both the spatial mismatches between workplaces, homes, schools and nurseries, and the associated tensions between the different time schedules of these activities. These spatial and temporal coordination issues become more complex as the number of children in the household increase (Jarvis, 2005; Skinner, 2003). Finally, Part V focuses more directly on policies and processes that promote or impede progress towards gender equality (Rees, this volume).

In the Conclusion we try to draw together the implications of the different case studies and reflect more generally on whether and in what ways contemporary changes in the labour market have altered gender divisions. We try to draw out the significance of different national policies in the context of greater economic homogenization. Although in many ways everyone is inextricably integrated into the global economy, the form of that integration still varies significantly between nation-states and examining the experiences of people in different countries helps to identify the opportunities and tensions in different policy approaches for moving us towards a position of greater gender equity. We argue that this requires a focus on outcomes for different groups of men and women in different structural positions as well as on the possibly contradictory gender effects of policies in different social arenas. In this sense policies are required that not only enable people (women in 
particular) to meet their practical interests to manage work and life, but also meet more strategic interests of gender equity such as challenging the gendered division of responsibilities for social reproduction; which would allow fathers to share in caring for their children and allow women to be engaged in paid work which is necessary to ensure their economic welfare, given the increase in likelihood that they will at some point in their lives have to be economically independent.

Finally we consider in a more speculative way what kind of social or spatial agenda would promote a sustainable and equitable work-life balance in knowledge-based economies. Are we too trapped or conditioned by our own world and current patterns to envisage a system in which there is a genuinely greater sharing of roles? Or is the current division of labour by task between women and men - although not the association with unequal monetary rewards - the preferred one? Public policies in a wide range of nation-states have changed significantly in terms of their rhetoric, in the range of issues that they now consider within their 'competency' and in terms of practical policies. By exploring the experiences of different countries it is possible to see how divisions of labour between household members, men and women, and between the family, the state and the private sector, vary and the extent to which the different division of responsibilities facilitates a society where differentiation may remain but where differentiation by tasks does not lead to differentiation in economic well-being.

\section{NOTES}

1. The exception is the chapter by Harriet Presser. Other papers from the series - Brannen, Doogan, Jarvis, and Rubery, Ward, Grimshaw and Beynon - together with an introduction by the editors which reflects on the different understanding of the new economy, have been published in a special issue of Time and Society (2005).

2. See Williamson (2004).

3. Ruth Emerek refers to this as the 'sandwich generation'; see Emerek (1998).

4. These strategies and their associated targets, for example for levels of employment or childcare, are negotiated by member states through the Open Method of Coordination which commits member states to work together towards shared goals but does not seek to homogenize their inherited policy regimes and institutional arrangements.

5. Recent data shows that the EU's employment rate grew at a rate of 0.2 per cent in 2003 compared to 0.9 per cent in the US, the EU employment rate is 63 per cent compared to 69.9 per cent in the US and the unemployment rate is higher 9.1 per cent compared to 6 per cent in the US (European Commission, 2004b).

6. These targets were set in the Barcelona council of 2002.

7. See for example the Millennium Development Goals (UNDP (2003), empowerment strategies and the European Union's Strategy for Gender Equality (EC, 2000b), see also OECD (2002).

8. 85 Broads was originally founded in 1999 as a network for current and former Goldman Sachs women professionals and is now a wider group with women MBAs from the leading graduate business schools and colleges, and women professionals from over 450 companies. The name of the group is a word play on GS's HQ address which is 85 Broad St., New York. 
9. In December 2004 some relaxation of the 35-hour working week was introduced with the amount of permitted overtime per year being raised by 40 hours from 180 to 220 , and employees will also be encouraged to sell back to their employer the compensatory days off they earn by working more than 35 hours. 
Diane Perrons, Linda McDowell, Colette Fagan, Kath Ray, and Kevin Ward - 9781845428976 Downloaded from PubFactory at $04 / 26 / 2023$ 02:18:45PM via free access 